\title{
Analysis of the Effect of Clinical Application of Detailed Nursing Measures in Ensuring the Safety of Nursing in Operating Room
}

\author{
SHUAI WANG AND Y. H. CHEN ${ }^{1 *}$ \\ Department of Operating Room, ${ }^{1}$ Department of Nursing, Nanjing First Hospital, Nanjing Medical University, Nanjing 210006 , \\ Jiangsu, China
}

Wang et al.: Detailed Nursing Measures in Ensuring the Safety of Nursing in Operating Room

\begin{abstract}
To discuss the clinical application effect analysis of detailed nursing measures in ensuring the safety of nursing in the operating room is the objective. 140 patients who were admitted in the operating room of our hospital from December 2018 to December 2020 were randomly selected as the research objects. According to the computer random allocation method, they were divided into the control group and the experimental group, with 70 patients in each group. The control group was given routine nursing care and the intervention group was given detailed nursing care. The two groups were observed and compared the nursing quality scores, the rate of nurse-patient disputes and error rates, self-rating depression scale and self-rating anxiety scale scores, nursing satisfaction rate and complications. The results showed that compared with the control group, the intervention group had higher nursing quality scores, higher nursing satisfaction rate and postoperative self-rating depression scale and self-rating anxiety scale scores, lower nursing-patient disputes and complications and the differences were statistically significant $(p<0.05)$. Detailed nursing measures improve the quality of care, relieve patient's anxiety and depression, increase patient satisfaction, significantly reduce postoperative complications and provide a guarantee for ensuring the safety of nursing care in the operating room.
\end{abstract}

Key words: Nursing care, self-rating depression scale, self-rating anxiety scale

The operating room is a product of the combination of modern medical technology and engineering technology and is the core part of hospital surgery ${ }^{[1]}$. It embodies the level of facilities, medical care and management of modern hospitals ${ }^{[2]}$. As an important part of the quality of the operating room, nursing quality has the characteristics of high technical level, long working hours, large workload and certain risks and its attention to detail management ${ }^{[3,4]}$. The quality of care is not only an important indicator of the quality of medical services, but also a microcosm of the quality level of the entire hospital operating room ${ }^{[5,6]}$. Poor care will increase the mortality rate and many care accidents, which will seriously affect the patient's prediction ${ }^{[7,8]}$.

In recent years, there have been frequent disputes between nurses and patients in the operating room, partly due to the hidden safety hazards in operating room nursing ${ }^{[9]}$, such as: receiving the wrong patient before the operation, receiving the wrong operation time, etc.; intraoperative equipment and medicines are

*Address for correspondence

E-mail: yuhongchen2021@163.com

Special Issue 3, 2021 not fully equipped and they may even disappear, the device remains in the patient; the post-operative work with the nurse in the ward is not careful enough and important information is omitted; the above-mentioned potential safety hazards will reduce the quality of care and may cause major medical accidents at any time ${ }^{[10]}$. Therefore, as the health care environment becomes more complex and focused details, detailed care has become the trend of modern medical care ${ }^{[11]}$. Detailed nursing focuses on the fundamental interests of patients, making the nursing work in the operating room precise and standardized. Therefore, in this study, detailed nursing care was given to surgical patients, in order to improve the quality and efficiency of nursing work in the operating room, improve patient care satisfaction and reduce postoperative adverse events, so as to provide reference for clinical treatment and nursing.

\section{MATERIALS AND METHODS}

\section{General information}

140 patients admitted to the operating room of our hospital from December 2018 to December 2020

\footnotetext{
Indian Journal of Pharmaceutical Sciences
} 
were taken as the research objects and the randomized experiment method was adopted to divide the patients into the experimental group and the control group at random. The informed consent of the patient is obtained in advance and communication is not possible, except for patients with severe mental illness.

\section{Methods}

Patients in the control group were given routine surgical nursing intervention; while the patients in the intervention group were given detailed nursing intervention on the basis of routine nursing intervention. The specific methods are as follows:

\section{Preoperative intervention:}

Psychological intervention; Communicate with patients. Some patients are prone to anxiety, tension and other negative emotions before surgery. Nursing staff can understand the patients negative emotions through communication, help patients overcome fear, anxiety and other negative emotions and give them humanity. Caring, explaining the purpose of surgery, procedures, precautions after surgery and previous successful cases for patients, so that patients and their families can be psychologically prepared in advance, actively cooperate and build confidence in the surgery.

To receive patients before surgery, strictly abide by the verification system to prevent the possibility of receiving the wrong patient or the wrong operation room. At the same time, pay attention to whether the patient carries valuables with them to avoid loss and cause unnecessary conflicts.

Strictly check the regular disinfection of instruments and equipment. For patients with special infectious diseases such as acquired immune deficiency syndrome (AIDS) and hepatitis B, pay attention to strengthen the disinfection treatment and keep the complete sterilization effect data.

\section{Intraoperative care:}

The nursing staff should move gently when moving the patient, coordinate with the doctor to put the required surgical position and at the same time strengthen the effective protection of the patient's privacy. In order to ensure the quality of care, carefully record the operation, closely observe the changes in the patient's vital signs and be alert for adverse reactions such as allergies during anesthesia. Monitor the working status of surgical instruments in real time, carefully check the instruments and gauze used in the operation, carefully check the surgical incision and prevent the instruments or gauze from falling into the patient's body. Strictly manage the intraoperative pathological specimens, comply with the verification system, and send special personnel to the pathology department in time.

\section{Postoperative care:}

When handing over to the ward nurse, check the patient's skin condition, the patency of the venous channels and other drainage tubes and whether there is bleeding from the surgical incision. Pay attention to protect the privacy of patient's and it is not allowed to inform others about the health and privacy of patients. Regular follow-up visits will be conducted on the 1 , 3 and $7 \mathrm{~d}$ after surgery to check the patient's surgical incision, understand the patient's mental state and provide psychological counseling if necessary.

\section{Statistical methods}

All analyses were performed using the statistical software EmpowerStats (http://www.enabledstats. com). Count data is expressed as $\mathrm{n}(\%)$, using $\mathrm{X}^{2}$ test, measurement data is expressed as $\mathrm{x} \pm \mathrm{s}$, using $\mathrm{t}$ test, the difference is statistically significant with $\mathrm{p}<0.05$.

\section{RESULTS AND DISCUSSION}

There were 70 patients in the intervention group, aged from 29 to $81 \mathrm{y}$ old, with an average age of $53 \mathrm{y}$ old. There were 36 women in the intervention group. The source of the patient departments is as follows: 20 cases of general surgery, 21 cases of obstetrics and gynecology, 5 cases of neurosurgery, 10 cases of orthopedics and 14 cases of urology. There were 70 patients in the control group, ranging in age from 30 to $82 \mathrm{y}$ old, with an average age of $53 \mathrm{y}$ old. There were 37 females. The source of the patient departments is as follows: 22 cases of general surgery, 22 cases of obstetrics and gynecology, 3 cases of neurosurgery, 8 cases of orthopedics and 15 cases of urology. There was no significant difference in baseline data between the two groups (Table 1).

The nursing quality score is based on disinfection and isolation, medical and nursing cooperation, equipment preparation, equipment management and nursing quality and safety, each item is $0-100$ points, the higher the score, the better the effect. The medical and nursing cooperation, equipment preparation and nursing quality and safety of the intervention group were significantly higher than those of the control group $(\mathrm{p}>0.05)$ and there was no significant difference between the two groups in equipment management (Table 2 and fig. 1). 
The nurse-patient dispute rate of the intervention group was $2.9 \%$, which was significantly lower than 12.9 $\%$ of the control group $(p<0.05)$; the error rate of the intervention nurses was also lower than that of the control group, but it was not statistically significant $(\mathrm{p}>0.05)$ as shown in Table 3 and fig. 2 .

Compare the 12 scores of the two groups of patients on the self-rating depression scale (SDS) ${ }^{[12]}, 25$ to 49 indicate no depression, 50-59 indicate mild to moderate depression, 60-69 indicates moderate to severe depression and a score of 70 or above indicates severe depression. Comparing the self-rating anxiety scale (SAS) score ${ }^{[13]}, 50-59$ is divided into mild anxiety; 6069 is divided into moderate anxiety; more than 70 is divided into severe anxiety. There was no significant difference in baseline anxiety and depression scores between the two groups. After reassessment, it can be seen that the anxiety score and depression score of the intervention group were reduced more significantly than the control group and the difference was statistically significant $(\mathrm{p}<0.05)$, Table 4 and fig. 3.
The Newcastle satisfaction with nursing scales (NSNS) was used to evaluate the nursing service satisfaction rate of the two groups. The content of NSNS is judged as very dissatisfied, dissatisfied, fair, satisfied and very satisfied. Total satisfaction rate $=$ satisfaction rate+very satisfied rate ${ }^{[14]}$. The total satisfaction rate of the intervention group was significantly higher than that of the control group $(\mathrm{p}<0.05)$, as shown in Table 5 .
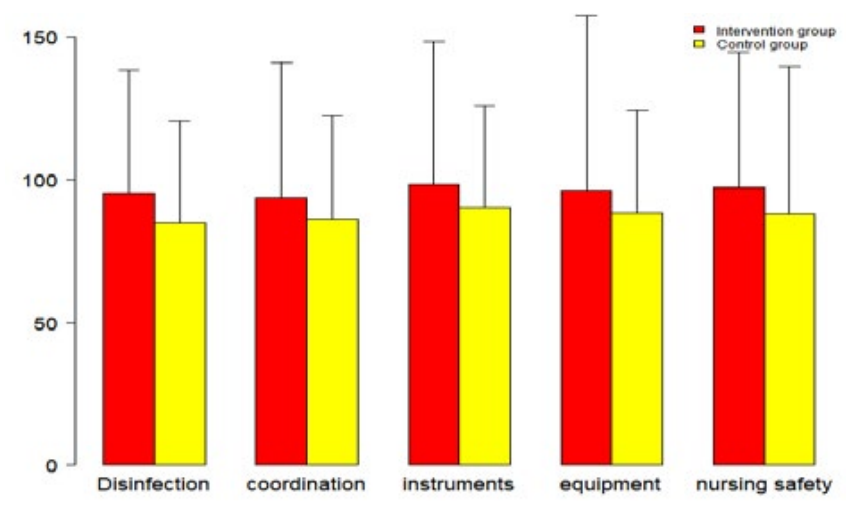

Fig. 1: Comparison of nursing quality scores between the two groups

TABLE 1: BASELINE DATA OF THE TWO GROUPS OF PATIENTS

\begin{tabular}{|c|c|c|c|c|}
\hline Contents & Intervention group $(n=70)$ & Control group $(n=70)$ & $t / X^{2}$ & $\mathrm{p}$ \\
\hline Age $(y)$ & $53.1 \pm 16.1$ & $52.5 \pm 17.9$ & 0.20 & 0.83 \\
\hline Gender: Female & $36(51.4 \%)$ & 37 (52.9 \%) & 0.03 & 0.86 \\
\hline \multicolumn{5}{|l|}{ Department source } \\
\hline General surgery & $20(33.3 \%)$ & $22(36.7 \%)$ & 0.15 & 0.70 \\
\hline Obstetrics and gynecology & $21(35.0 \%)$ & $22(36.7 \%)$ & 0.04 & 0.85 \\
\hline Neurosurgery & $8(11.4 \%)$ & $3(4.3 \%)$ & 2.47 & 0.11 \\
\hline Orthopedics & 7 (10.0 \%) & $8(13.3 \%)$ & 1.02 & 0.06 \\
\hline Urology & $14(23.3 \%)$ & $15(25.0 \%)$ & 0.05 & 0.83 \\
\hline
\end{tabular}

TABLE 2: COMPARISON OF NURSING QUALITY SCORES BETWEEN THE TWO GROUPS

\begin{tabular}{|c|c|c|c|c|}
\hline Contents & Intervention group $(\mathrm{n}=70)$ & Control group $(n=70)$ & $\mathrm{t}$ & $\mathbf{p}$ \\
\hline Disinfection and isolation & $95.2 \pm 22.1$ & $85.1 \pm 18.2$ & 2.95 & 0.003 \\
\hline Medical and nursing cooperation & $93.6 \pm 24.2$ & $86.2 \pm 18.5$ & 2.04 & 0.04 \\
\hline Equipment preparation & $98.4 \pm 25.6$ & $90.2 \pm 18.3$ & 2.18 & 0.03 \\
\hline Equipment management & $96.4 \pm 31.1$ & $88.3 \pm 18.4$ & 1.91 & 0.06 \\
\hline Care quality and safety & $97.3 \pm 24.3$ & $88.1 \pm 26.4$ & 2.19 & 0.02 \\
\hline
\end{tabular}

TABLE 3: COMPARISON OF NURSE-PATIENT DISPUTE RATE AND ERROR RATE BETWEEN THE TWO GROUPS [n (\%)]

\begin{tabular}{|c|c|c|c|c|}
\hline Contents & Intervention group $(n=70)$ & Control group $(n=70)$ & $\mathrm{X}^{2}$ & $\mathrm{p}$ \\
\hline Nurse-patient dispute rate & $2(2.9 \%)$ & $9(12.9 \%)$ & 4.83 & 0.02 \\
\hline Error rate & $1(1.4 \%)$ & $6(8.6 \%)$ & 3.76 & 0.06 \\
\hline
\end{tabular}

TABLE 4: THE SCORES OF THE SDS AND SAS OF THE TWO GROUPS

\begin{tabular}{lccccc}
\hline Scale & Intervention & Intervention group $(\mathrm{n}=70)$ & Control group $(\mathrm{n}=\mathbf{7 0})$ & $\mathrm{t}$ & $\mathrm{p}$ \\
\hline \multirow{2}{*}{ SDS } & Before intervention & $67.1 \pm 16.1$ & $66.7 \pm 15.9$ & 0.36 & 0.71 \\
& After intervention & $45.3 \pm 10.1$ & $51.2 \pm 12.9$ & -2.78 & 0.006 \\
\multirow{2}{*}{ SAS } & Before intervention & $55.6 \pm 15.1$ & $58.1 \pm 16.4$ & -1.00 & 0.31 \\
& After intervention & $35.4 \pm 13.6$ & $41.3 \pm 15.1$ & -2.24 & 0.02 \\
\hline
\end{tabular}


The incidence of pressure ulcers, soft tissue injury and total complications in the intervention group was significantly lower than that in the control group $(p<0.05)$, while the incidence of deep vein thrombosis and infection was not significantly different between the two groups ( $>00.05)$ as shown in Table 6 and fig. 4 .

As a key department of the hospital, the operating room is an important place for surgical patients to undergo surgery, interventional treatment, examination and rescue $^{[15]}$ compared with other departments, medical errors in the operating room may bring catastrophic consequences to patients ${ }^{[16]}$. As an indispensable part of the operating room team, nurses require high specialized nursing skills and comprehensive qualities. The quality of nursing care in the operating room will directly affect the operation of the entire surgical system $^{[17]}$. Health care systems around the world are facing the challenge of improving the quality of care and reducing the risk of adverse events ${ }^{[18,19]}$. "Details
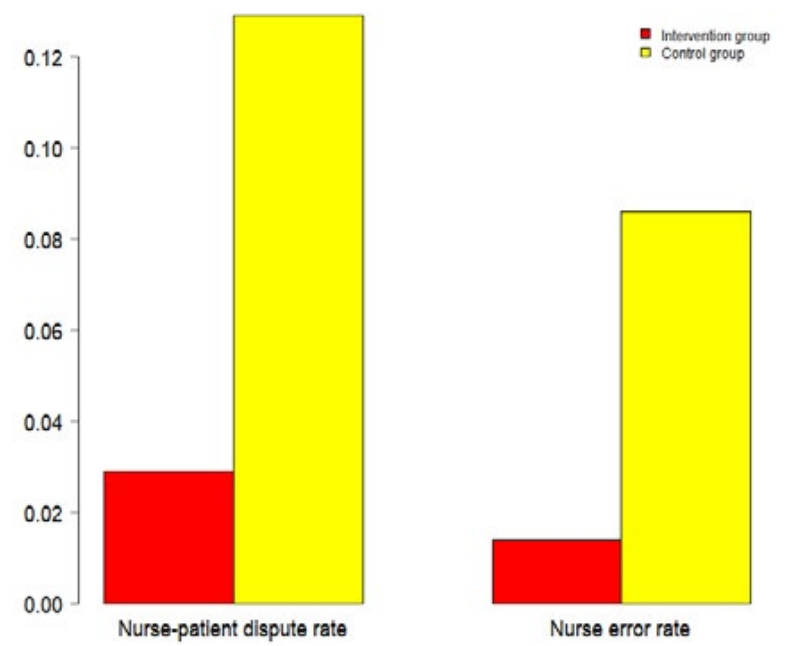

Fig. 2: Comparison of nurse-patient dispute rate and error rate between the two groups determine success or failure", detailed care emphasizes adequate preoperative preparation, tacit cooperation during the operation and follow-up in place after the operation, which is more in line with the purpose
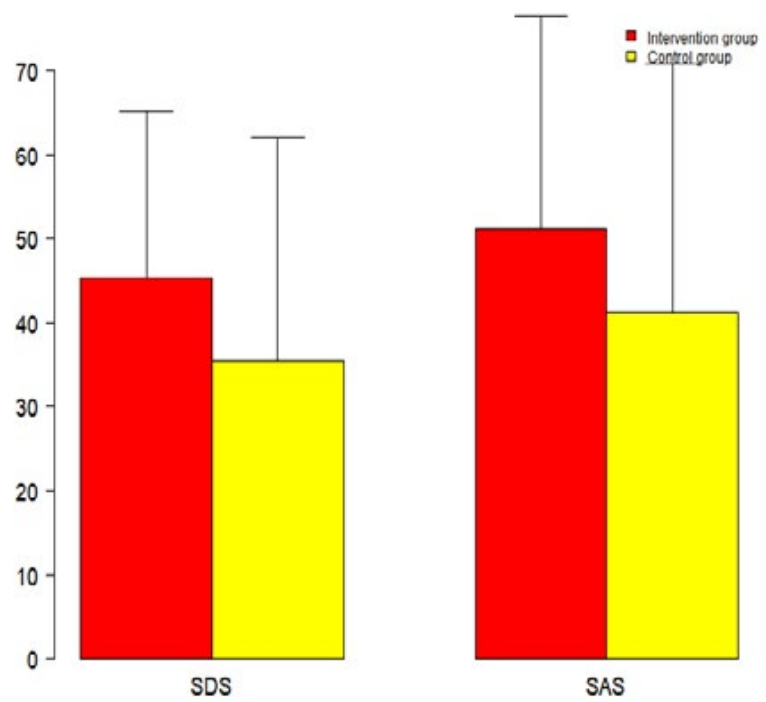

Fig. 3: The scores of the SDS and SAS of the two groups after intervention

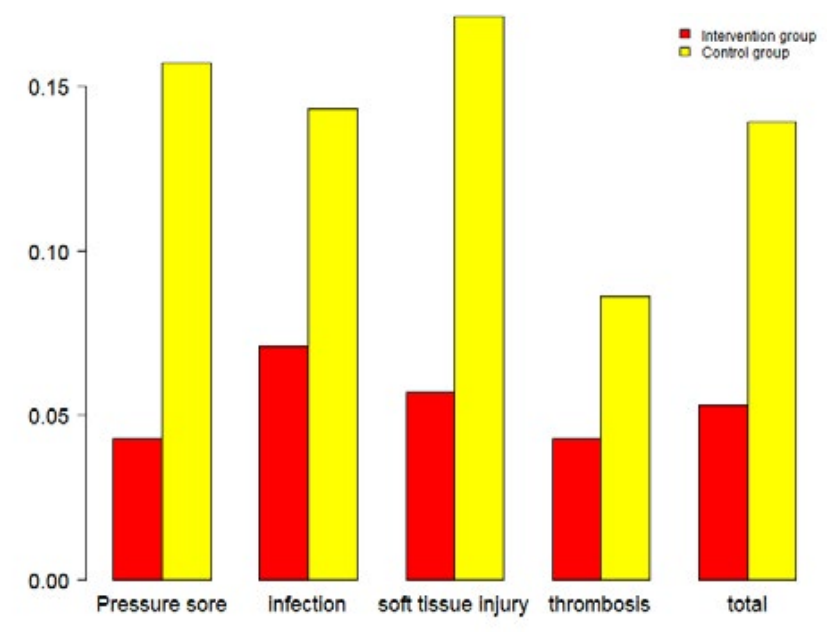

Fig. 4: Comparison of complications between the two groups

TABLE 5: COMPARISON OF NURSING SERVICE SATISFACTION BETWEEN THE TWO GROUPS [n (\%)]

\begin{tabular}{lcccccc}
\hline Contents & $\begin{array}{c}\text { Very } \\
\text { dissatisfied }\end{array}$ & Dissatisfied & Fair & Satisfied & Very satisfied & $\begin{array}{c}\text { Total satisfaction } \\
\text { rate }\end{array}$ \\
\hline Intervention & $0(0 \%)$ & $1(1.4 \%)$ & $2(2.8 \%)$ & $32(45.7 \%)$ & $35(50 \%)$ & $67(95.7 \%)$ \\
group & $3(4.3 \%)$ & $5(7.1 \%)$ & $8(11.4 \%)$ & $28(40 \%)$ & $26(37.1 \%)$ & $60(85.3 \%)$ \\
Control group & & & & & & 4.16 \\
$X^{2}$ & & & & & & 0.04 \\
$\mathrm{p}$ & & & & & \\
\hline
\end{tabular}

TABLE 6: COMPARISON OF COMPLICATIONS BETWEEN THE TWO GROUPS

\begin{tabular}{lcccc}
\hline Contents & Intervention group $(\mathbf{n}=\mathbf{7 0})$ & Control group $(\mathbf{n}=\mathbf{7 0})$ & $\mathbf{X}^{2}$ & $\mathrm{p}$ \\
\hline Pressure sore & $3(4.3 \%)$ & $11(15.7 \%)$ & 5.08 & 0.02 \\
infection & $5(7.1 \%)$ & $10(14.3 \%)$ & 1.87 & 0.17 \\
Soft tissue injury & $4(5.7 \%)$ & $12(17.1 \%)$ & 4.52 & 0.03 \\
Deep vein thrombosis & $3(4.3 \%)$ & $6(8.6 \%)$ & 1.07 & 0.30 \\
Total complications & $15(5.36 \%)$ & $39(13.93 \%)$ & 11.81 & 0.006 \\
\hline
\end{tabular}


TABLE 7: COMPARISON OF AVERAGE RECOVERY TIMEAND INCIDENCE OF DELAYED ENCEPHALOPATHY BETWEEN THE TWO GROUPS

\begin{tabular}{lccc}
\hline Group & Number of cases & Average recovery time $(\overline{\mathrm{x}} \pm \mathrm{s}, \mathrm{h})$ & Incidence of delayed encephalopathy [n (\%)] \\
\hline Control group & 52 & $26.32 \pm 6.14$ & $7(13.46)$ \\
Observation Group & 52 & $18.55 \pm 4.23^{\#}$ & $1(1.92)^{\#}$ \\
\hline
\end{tabular}

Note: Comparison with control group, ${ }^{*} \mathrm{p}<0.05$

of modern nursing "patient-centered and patientoriented"[20]. This article discusses the effect of detailed nursing on the safety of surgical nursing. The results of the study show that detailed nursing can significantly improve the quality of care and relieve the anxiety and depression of patients while making the nursing work fine and standard. Satisfaction reduces the occurrence of conflicts between nurses and patients and significantly reduces postoperative complications.

The traditional nursing model has some drawbacks. Due to its backward leaning concept and the same way of thinking, this method cannot fully adapt to the rapid development of the medical industry ${ }^{[21,22]}$. Nursing is an expression of care $^{[23]}$ in order to reduce the possibility of unresolved fundamental care, thereby helping to provide a higher quality of care and a safer mode of care ${ }^{[24,25]}$. Detailed care, emphasizing the person being cared for, instead of focusing on a fixed person or a certain surgical site, can provide safer care and higher quality of care.

Our study has some limitations. Due to the small sample size of our study, only 120 cases, it is not ruled out that some errors may be caused to the research results; secondly, our research population is mainly for Chinese people, so this result needs to be carefully interpreted in other populations research, the result brings some errors.

Detailed care significantly improves the quality of care, relieves patient's anxiety and depression, increases patient satisfaction, significantly reduces postoperative complications and provides a guarantee for ensuring the safety of nursing care in the operating room.

\section{Conflicts of Interest:}

The authors declared no conflict of interest.

\section{REFERENCES}

1. Martinez-Millana A, Lizondo A, Gatta R, Vera S, Salcedo VT, Fernandez-Llatas C. Process mining dashboard in operating rooms: Analysis of staff expectations with analytic hierarchy process. Int J Environ Res Public Health 2019;16(2):199.

2. Facco Rodrigues V, da Rosa Righi R, Andre da Costa C, Eskofier B, Maier A. On providing multi-level quality of service for operating rooms of the future. Sensors 2019;19(10):2303.

3. Abdollahi T, Pedram Razi S, Pahlevan D, Yekaninejad MS,
Amaniyan S, Leibold Sieloff C, et al. Effect of an ergonomics educational program on musculoskeletal disorders in nursing staff working in the operating room: A Quasi-randomized controlled clinical trial. Int $\mathrm{J}$ Environ Res Public Health 2020;17(19):7333.

4. Leong KB, Hanskamp-Sebregts M, van der Wal RA, Wolff AP. Effects of perioperative briefing and debriefing on patient safety: a prospective intervention study. BMJ Open 2017;7(12):e018367.

5. McHugh MD, Stimpfel AW. Nurse reported quality of care: a measure of hospital quality. Res Nurs Health 2012;35(6):56675.

6. Duan X, Shi Y. Current status of quality evaluation of nursing care through director review and reflection from the nursing quality control centers. Int J Clin Exp Med 2014;7(10):373745.

7. Gillespie BM, Harbeck E, Kang E, Steel C, Fairweather N, Chaboyer W. Correlates of non-technical skills in surgery: a prospective study. BMJ Open 2017;7(1):e014480.

8. Halfon P, Staines A, Burnand B. Adverse events related to hospital care: a retrospective medical records review in a Swiss hospital. Int J Qual Health Care 2017;29(4):527-33.

9. Rohsig V, Maestri RN, Mutlaq MF, de Souza AB, Seabra A, Farias ER, et al. Quality improvement strategy to enhance compliance with the World Health Organization Surgical Safety Checklist in a large hospital: Quality improvement study. Ann Med Surg 2020;55:19-23.

10. Anderson O, Davis R, Hanna GB, Vincent CA. Surgical adverse events: a systematic review. Am J Surg 2013;206(2):253-62.

11. Lee Y, Oh Y. Levels, antecedents, and consequences of critical thinking among clinical nurses: a quantitative literature review. J Educ Eval Health Prof 2020;17:26.

12. Deng D, Zhou A, Chen P, Shuang Q. CODEXS: a new multidimensional index to better predict frequent COPD exacerbators with inclusion of depression score. Int $\mathrm{J}$ Chron Obstruct Pulmon Dis 2020;15:249-59.

13. Knight RG, Waal-Manning HJ, Spears GF. Some norms and reliability data for the State-Trait Anxiety Inventory and the Zung Self-Rating Depression scale. Br J Clin Psychol 1983;22(4):245-9.

14. Zhang J, Yang L, Wang X, Dai J, Shan W, Wang J. Inpatient satisfaction with nursing care in a backward region: a cross-sectional study from northwestern China. BMJ Open 2020;10(9):e034196.

15. Lee DJ, Ding J, Guzzo TJ. Improving operating room efficiency. Curr Urol Rep 2019;20(6):1-8.

16. Weld LR, Stringer MT, Ebertowski JS, Baumgartner TS, Kasprenski MC, Kelley JC, et al. TeamSTEPPS improves operating room efficiency and patient safety. Am J Med Qual 2016;31(5):408-14.

17. Hardy K, Metcalfe J, Clouston K, Vergis A. The Impact of an Acute Care Surgical Service on the Quality and Efficiency of Care Outcome Indicators for Patients with General Surgical Emergencies. Cureus 2019;11(6):e5036.

18. Scott SD, Rotter T, Hartling L, Chambers T, Bannar-Martin $\mathrm{KH}$. A protocol for a systematic review of the use of process 
evaluations in knowledge translation research. Syst Rev 2014;3(1):149.

19. Ordi J, Castillo P, Garcia-Basteiro AL, Moraleda C, Fernandes F, Quinto L, et al. Clinico-pathological discrepancies in the diagnosis of causes of death in adults in Mozambique: a retrospective observational study. PLoS One 2019;14(9):e0220657.

20. Ngo-Metzger Q, Legedza AT, Phillips RS. Asian American's reports of their health care experiences. J Gen Intern Med 2004;19(2):111-9.

21. Li W, Gao J, Wei S, Wang D. Application values of clinical nursing pathway in patients with acute cerebral hemorrhage. Exp Ther Med 2016;11(2):490-4.

22. Pepito JA, Locsin R. Can nurses remain relevant in a technologically advanced future? Int J Nurs Sci 2019;6(1):10610.

23. Adraro Z, Mengistu D. Implementation and factors affecting the nursing process among nurses working in selected government hospitals in Southwest Ethiopia. BMC Nurs 2020;19(1):105.

24. Andersson EK, Willman A, Sjöström-Strand A, Borglin G. Registered nurses' descriptions of caring: a phenomenographic interview study. BMC Nurs 2015;14(1):1-10.

25. Oliver A, Galiana L, Simone GD, Tomas JM, Arena F, Linzitto $\mathrm{J}$, et al. Palliative care professionals' inner lives: Cross-cultural application of the awareness model of self-care. Healthcare 2021;9(1):81.

This is an open access article distributed under the terms of the Creative Commons Attribution-NonCommercial-ShareAlike 3.0 License, which allows others to remix, tweak, and build upon the work non-commercially, as long as the author is credited and the new creations are licensed under the identical terms

This article was originally published in a special issue,
"Evolutionary Strategies in Biomedical Research and
Pharmaceutical Sciences" Indian J Pharm Sci 2021:83(3)
Spl issue;174-179

